\title{
Orthodontic incisor retraction caused changes in the soft tissue chin area: a retrospective study
}

Wenxin $\mathrm{Lu}^{1+}, \mathrm{Xu}$ Zhang $^{1 \dagger}$, Li Mei ${ }^{2^{*}}$, Pengfei Wang ${ }^{1}$, Jiarong $\mathrm{He}^{1}, \mathrm{Yu} \mathrm{Li}^{1^{*}}$ and Zhihe Zhao ${ }^{1}$

\begin{abstract}
Background: To investigate the area and morphological changes around the soft tissue chin after orthodontic incisor retraction.

Methods: Fifty-nine female adults with bimaxillary protrusion requiring extraction of four premolars were included in the study. Cephalograms were taken before (T0) and after (T1) orthodontic treatment. The soft tissue changes, including the area, thickness and morphology were measured. Paired-t tests were performed for statistical comparisons. Pearson correlation analyses and backward multivariate regression analyses were used to identify the relationship between the soft tissue changes and incisor retraction.

Results: Following the incisor retractions ( $5.35 \pm 1.79 \mathrm{~mm}$ and $4.42 \pm 1.62 \mathrm{~mm}$ for the upper and lower, respectively), there was a significant increase in the soft tissue thickness of L1C-LL $(0.64 \pm 1.67 \mathrm{~mm}, P=0.025)$ and Pog-Pog' $(0.44 \pm 1.10 \mathrm{~mm}, P=0.022)$, and a significant decrease in the soft tissue thickness of $B-B^{\prime}(1.21 \pm 1.34 \mathrm{~mm}, P<0.01)$. Changes in the area of soft tissue chin and lower lip were not statistically significant $(P>0.05)$. Pearson coefficient between the thickness changes of $B-B^{\prime}$ and the retraction of lower incisors was -0.376 . The multiple correlations between the soft tissue thickness changes and incisor retractions were $Y=1.02-0.42 a+0.42 b$ for $L 1 C-L L$, and $Y=$ $0.17-0.316$ for B-B'.
\end{abstract}

Conclusions: The orthodontic incisor retraction could cause soft tissue thickness changes (i.e. an increase in L1C-LL and Pog-Pog' and a decrease in B-B') without area changes.

Keywords: Bimaxillary protrusion, Soft tissue change, Tooth extraction, VTO

\footnotetext{
* Correspondence: li.mei@otago.ac.nz; yuli@scu.edu.cn

${ }^{+}$Wenxin Lu and Xu Zhang contributed equally to this work and should be regarded as co-first authors.

${ }^{2}$ Discipline of Orthodontics, Department of Oral Sciences, Faculty of Dentistry, Sir John Walsh Research Institute, University of Otago, Dunedin, New Zealand

${ }^{1}$ State Key Laboratory of Oral Diseases, National Clinical Research Center for Oral Diseases, Department of Orthodontics, West China Hospital of Stomatology, Sichuan University, 14 Renmin South Road Third Section, Chengdu 610041, China
}

(c) The Author(s). 2020 Open Access This article is licensed under a Creative Commons Attribution 4.0 International License, which permits use, sharing, adaptation, distribution and reproduction in any medium or format, as long as you give appropriate credit to the original author(s) and the source, provide a link to the Creative Commons licence, and indicate if changes were made. The images or other third party material in this article are included in the article's Creative Commons licence, unless indicated otherwise in a credit line to the material. If material is not included in the article's Creative Commons licence and your intended use is not permitted by statutory regulation or exceeds the permitted use, you will need to obtain permission directly from the copyright holder. To view a copy of this licence, visit http://creativecommons.org/licenses/by/4.0/. The Creative Commons Public Domain Dedication waiver (http://creativecommons.org/publicdomain/zero/1.0/) applies to the data made available in this article, unless otherwise stated in a credit line to the data. 


\section{Background}

Facial appearance plays an important role in an individual's daily life, social interactions, self-esteem and psychological well-being [1]. It has been found that the public increasingly pays attention to the lips and soft tissue chin rather than to other orofacial structures when assessing facial esthetics [2]. The soft tissue chin in patients with dental protrusion, however, is strained resulting in undermined chin prominence [3]. The orthodontic treatment of bimaxillary protrusive patients usually involves the extraction of premolars and retraction of anterior teeth, which results in increased chin prominence and improved facial profiles [4]. Several studies and clinical trials have shown that these changes of soft tissue chin were mainly due to the redistribution or reshaping of the soft tissues around the chin area following the retraction of incisors [5].

Most of the previous studies used cephalometry and investigated the ratio between the amount of incisor retractions and soft tissue changes. For example, some researchers have reported the predictive ratios for lower lip change along with the mandibular incisor advancement ranging from 0.26 to $0.85: 1$, and $1: 1$ for the change of soft tissue pogonion to the advancement of hard tissue pogonion [6]. Others have suggested that there were significant individual variations for the changes in the soft tissue following the extraction treatment because of many influencing factors, such as soft tissue thickness, soft tissue areas, the underlying skeletal patterns [7], the soft tissue remodeling during orthodontic treatment and the strain of soft tissue upon the anterior teeth. Though it is now possible to simulate soft tissue changes for patients with dental protrusion and extraction treatment by using some visual treatment objective (VTO) software, it is still difficult to accurately predict the soft tissue changes in the chin area following the orthodontic incisor retraction [8-10].

Although the 3-dimensional cone-beam computed tomography (CBCT) has advantages for researching the hard and soft tissues changes following orthodontic treatment, the conventional 2-dimensional cephalogram is still of great clinical importance and commonly used in orthodontic diagnosis and treatment planning, due to the limitations of CBCT, such as high cost and radiation exposure [11]. An accurate prediction of soft tissue changes following incisor retraction using cephalograms has been considered to be clinically convenient and relevant for orthodontic treatment planning and doctorpatient communication [12].

The study aimed to measure the area and morphological changes in soft tissues around the chin following orthodontic incisor retraction in patients with bimaxillary dental protrusion, and to investigate the relationship between these soft tissue changes and the incisor retraction. The hypothesis was that the area around the soft tissue chin would enlarge and reshape following the incisor retraction.

\section{Methods \\ Subjects}

The study was designed as a retrospective observational study. Ethical approval for the study was obtained from the Ethics Committee of the West China Hospital of Stomatology, Sichuan University (WCHSIRB-ST-2017131). Written informed consent was obtained from each participant.

A total of 59 female adult patients (mean age $23.50 \pm$ 2.15 years, range $18-39$ years) were recruited in the study (Table 1). A sample size calculation was undertaken using the nQuery Adviser software package (Version 7.0; Statistical Solutions, Cork, Ireland). The pilot study [13] estimated that the effect size was 0.40. Based on a significance level of alpha 0.05 , the sample size was calculated to achieve an $80 \%$ power. The sample size calculation showed that 39 subjects were necessary.

Inclusion criteria were: (1) young female adults (1840 years old); (2) Skeletal Class I, Angle Class I bimaxillary dental protrusive malocclusion and crowding less than $4 \mathrm{~mm}$ in both arches with normal overjet and overbite; (3) wore stainless steel brackets (Victory Series, $3 \mathrm{M}$ Unitek, Monrovia, California, USA) with extraction of four premolars and anchorage reinforcements, including transpalatal arch, Nance button, headgear, and miniscrew. Exclusion criteria were: (1) previous surgery on the maxilla, mandible or chin; (2) history of craniofacial defects or syndromes, e.g. cleft lip and palates; (3) body weight change more than $5 \%$ during the orthodontic treatment.

\section{Cephalometric analysis}

The lateral cephalograms were taken before (T0) and after (T1) orthodontic treatment using a Cephalometer (Veraviewepocs, Morita, Kyoto, Japan). Each subject was positioned with the sagittal plane at a right angle to the path of the X-rays, the Frankfort plane paralleled to the horizontal, the teeth in centric occlusion, and the lips lightly closed. Dolphin Imaging software version 11.0 (Patterson Dental Supply, St. Paul, MN) was used for the cephalometric tracing and analysis.

The Frankfort Horizontal (FH) plane was used as the horizontal reference plane (Fig. 1). Two vertical lines

Table 1 Patients' age and weight at pre-treatment (TO) and post-treatment (T1)

\begin{tabular}{|c|c|c|c|c|c|c|}
\hline \multirow[t]{2}{*}{ Measurement } & \multicolumn{2}{|l|}{ T0 } & \multicolumn{2}{|l|}{ T1 } & \multicolumn{2}{|c|}{ Difference (T1-T0) } \\
\hline & Mean & SD & Mean & SD & Mean & SD \\
\hline Age (year) & $23.5(18-39)$ & 2.15 & $25.7(20-42)$ & 2.58 & 2.27 & 0.57 \\
\hline Weight (kg) & 55.68 & 2.81 & 55.08 & 2.60 & -0.60 & 1.38 \\
\hline
\end{tabular}




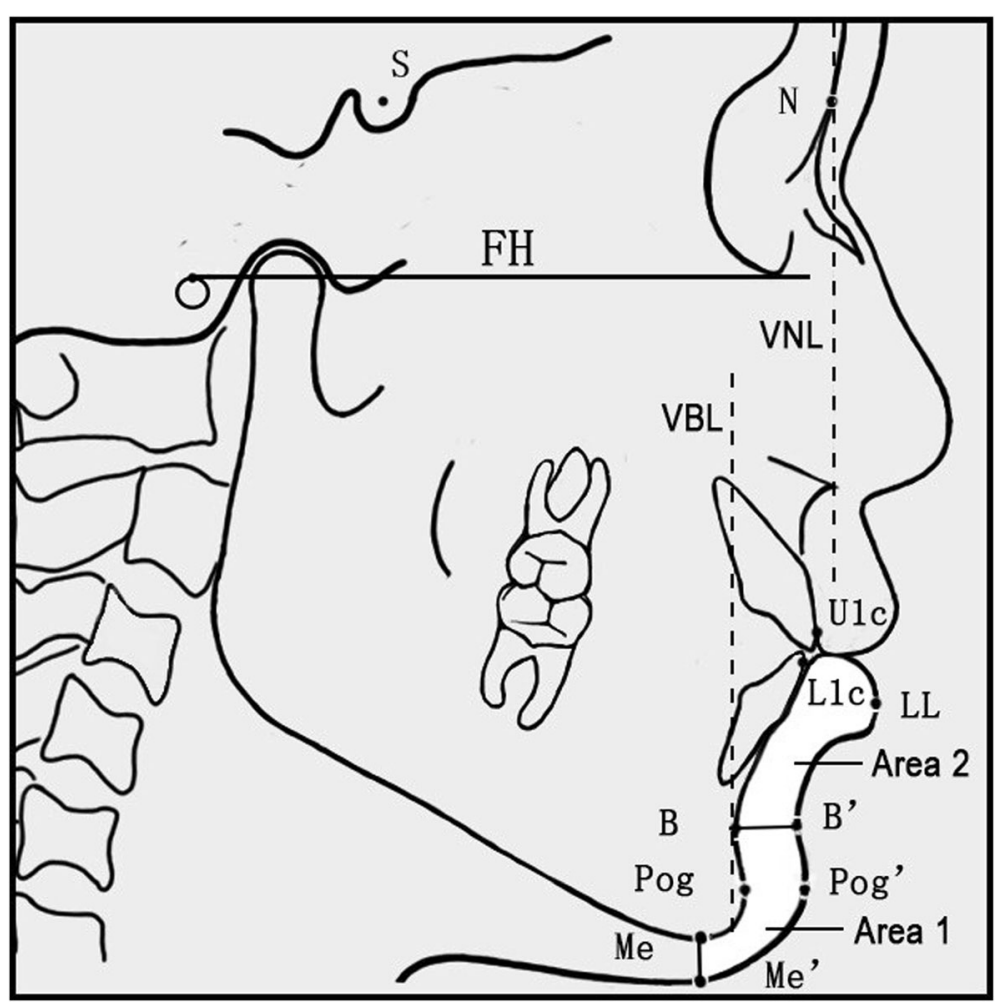

Fig. 1 Landmarks, reference planes and cephalometric measurements used in the study

perpendicular to the $\mathrm{FH}$ plane, one passing the $\mathrm{N}$ point (VNL) and the other passing the $\mathrm{B}$ point (VBL), served as the vertical reference lines for the maxillary and mandibular evaluations, respectively. Based on the literature $[14,15]$, the variables, including related cephalometric measurements, the amount of incisor retractions, two soft tissue areas (soft tissue chin and lower lip) and three soft tissue thicknesses (L1C-LL, B-B' and Pog-Pog') were illustrated in Fig. 1 and Table 2. The primary outcome variables were the changes of soft tissue area and thickness in response to the incisor retraction between pre-treatment and post-treatment. The secondary outcome variables included the changes of related cephalometric measurements between pre-treatment and post-treatment. The cephalometric radiographs before and after the treatment were superimposed on the cranial base to ensure consistency.

The amount of upper incisor retraction was the change of the horizontal distance between U1c and VNL before and after treatments. The amount of lower incisor retraction was the change of the horizontal distance between L1c and VBL before and after treatments. U1c and L1c were the most anterior points of the clinical crown of the upper and lower incisors, respectively (Fig. 1). Soft tissue thicknesses were the direct distances between the landmarks of L1c to LL, B to B' and Pog to Pog'. The areas of soft tissue chin and lower lip (i.e. Area 1 and 2 in Fig. 1) were measured in $\mathrm{mm}^{2}$ using a digital planimeter on Auto CAD 2016 (Autodesk, Inc. Saint Rafael, CA, USA) [16].

Both intra- and inter-operator reliabilities were evaluated using the Bland-Altman method and intraclass correlation coefficients. Briefly, thirty cephalograms were randomly selected and measured by two independent dental investigators. Each investigator repeated the measurements after 1 week. The inter-rater reliability was excellent (correlation coefficient was 0.90). The intrarater reliability was excellent (correlation coefficients for the two investigators were 0.95 and 0.91 ).

\section{Statistical analysis}

SPSS 19.0 (SPSS Inc., Chicago, IL, USA) was used for statistical analysis of the data. The skewness and kurtosis statistics demonstrated normal distributions. Paired-t tests were performed for statistical comparison of the soft tissue changes before and after the incisor retraction. Pearson correlation analysis and backward multivariate regression analysis were used to identify the relationships between the soft tissue changes and the incisor retractions. Multivariate regression models were established and derived as: $Y=$ Constant $+a+b$, where " $Y$ " was the soft tissue thickness change, and " $a$ " and " $b$ " were the coefficient values for the retraction of upper incisors and lower incisors, respectively. 
Table $\mathbf{2}$ Landmarks, reference planes and measurements used in the study

\begin{tabular}{|c|c|}
\hline & Definition \\
\hline \multicolumn{2}{|c|}{ Landmarks } \\
\hline $\mathrm{N}$ & Nasion: most anterior point of the frontonasal suture where the lines of the glabella profile meet those of the nasal bones \\
\hline S & Sella: Center of bony contour of sella turcica \\
\hline $\mathrm{P}$ & Porion: the midpoint of the upper contour of the metal ear rod of the cephalometer (machine porion) \\
\hline Or & Orbitale: the lowest point on the inferior margin of the orbit \\
\hline A & Most concave point between anterior nasalspine and superior prosthion \\
\hline U1 & The tip of the maxillary central incisors \\
\hline U1c & The most anterior point of clinical crown of maxillary central incisors \\
\hline L1 & The tip of the mandibular central incisors \\
\hline L1C & The most anterior point of clinical crown of mandibular central incisors \\
\hline B & Most concave point on mandibular symphysis \\
\hline Pog & Pogonion: the most anterior point on the osseous contour of the chin \\
\hline Me & Menton: the most inferior midline point on the mandibular symphesis \\
\hline LL & The most anterior point of the lower lip based on the reference plane \\
\hline Stmi & Uppermost point on vermilion border of lower lip \\
\hline $\mathrm{B}^{\prime}$ & The innermost point on the contour of the soft-tissue between the lower lip and the soft tissue chin \\
\hline Pog' & Soft tissue pogonion: the most prominent point on the chin based on the reference plane \\
\hline $\mathrm{Me}^{\prime}$ & Soft tissue menton: the lowest point on the contour of the soft tissue chin \\
\hline \multicolumn{2}{|c|}{ Reference planes } \\
\hline $\mathrm{FH}$ & Frankfurt Horizontal plane formed by Portion and Orbitale \\
\hline MP & Mandibular plane through Me and the lower margin of mandibular angle \\
\hline VBL & $\begin{array}{l}\text { A line passing through the B point and perpendicular to the } \mathrm{FH} \text { plane serving as the vertical reference for the mandibular } \\
\text { evaluations }\end{array}$ \\
\hline VNL & $\begin{array}{l}\text { A line passing through the } \mathrm{N} \text { point and perpendicular to the } \mathrm{FH} \text { plane serving as the vertical reference for the maxillary } \\
\text { evaluations }\end{array}$ \\
\hline
\end{tabular}

\section{Cephalometrics analysis index}

ANB $\left(^{\circ}\right)$

The ANB angle shows the difference between the maxilla and mandible

SNA $\left(^{\circ}\right)$

The SNA angle is used to establish the relationship of the maxilla to the cranial base

SNB $\left({ }^{\circ}\right)$

The SNB angle is used to establish the relationship of the mandible to the cranial base

U1-L1 ( $\left.{ }^{\circ}\right)$

Upper and lower central incisors Angle: the intersection Angle of the long axis of the upper and lower central incisors, representing the relative protrusion of the upper and lower central incisors

U1-NA $\left(^{\circ}\right) \quad$ The intersection Angle between the long axis of the upper central incisor and the NA line, representing the inclination of the upper central incisor

L1-NB $\left(^{\circ}\right) \quad$ The intersection Angle between the long axis of the lower central incisor and NB line, representing the inclination of the lower central incisor

SN-MP $\left(^{\circ}\right) \quad$ The Angle between the mandibular plane and the SN plane

FMA $\left(^{\circ}\right) \quad$ The Angle between the Frankfurt Horizontal plane and the Mandibular plane

Stmi-Me' (mm) Vertical distance between the landmarks of Stmi and Me'

\section{Soft tissue area measurements}

Area $1\left(\mathrm{~cm}^{2}\right) \quad$ The area of soft tissue chin from the border of B-B' till the border of Me-Me'

Area $2\left(\mathrm{~cm}^{2}\right) \quad$ The area of lower lip till the border of B-B'

\section{Soft tissue thickness measurements}

$\mathrm{L} 1 \mathrm{c}-\mathrm{LL}(\mathrm{mm})$

$B^{-} B^{\prime}(m m)$

Pog-Pog' (mm)
Distance between the landmarks of L1C and LL

Distance between the landmarks of B and B'

Distance between the landmarks of Pog and Pog' 


\section{Results}

Incisor retraction

The amount of upper incisor retraction was $5.35 \pm 1.79$ $\mathrm{mm}$ (95\% Confidence Interval (CI): 4.75-5.95 mm). The amount of lower incisor retraction was $4.42 \pm 1.62 \mathrm{~mm}$ (95\% CI: $3.88-4.96 \mathrm{~mm}$ ). The changes of related cephalometric measurements along with incisor retraction were shown in Table 3.

\section{Soft tissues area change}

No statistically significant difference of area change was found in the soft tissue chin (Area 1, T1-T0 $=0.14 \pm$ $0.50 \mathrm{~cm}^{2}, P=0.08$ ) or in the lower lip (Area 2, T1-T0 = $\left.-0.03 \pm 0.40 \mathrm{~cm}^{2}, P=0.69\right)$ with the incisor retraction (Table 4).

\section{Soft tissue thickness change}

Following the incisor retraction, there was a significant increase in the soft tissue thickness of L1c-LL (0.64 \pm $1.67 \mathrm{~mm}, P<0.05)$ and Pog-Pog' (0. $44 \pm 1.10 \mathrm{~mm}$, $P<0.05)$, and a significant decrease in the soft tissue thickness of B-B' $(1.21 \pm 1.34 \mathrm{~mm}, P<0.01)$ (Table 5).

\section{Relationship between the soft tissue thickness change and incisor retraction}

Pearson correlation analysis showed a negative correlation between the thickness change of $B-B^{\prime}$ and the lower incisor retraction (correlation coefficient $=-0.376$, $P<$ 0.05). No statistically significant correlation was found between the incisor retraction and the thickness change of L1c-LL and Pog-Pog' (Table 6).

\section{Multivariate regression analysis}

The multivariate regression analysis revealed that the multiple correlations between the soft tissue thickness changes and incisor retractions were $Y=1.02-0.42 a+$ $0.42 b$ for L1C-LL, and $Y=0.17-0.31 b$ for B-B' (" $Y$ " was the soft tissue thickness change, " $a$ " and " $b$ " were the

Table 3 Changes of cephalometric measurements between pre-treatment (T0) and post-treatment (T1)

\begin{tabular}{|c|c|c|c|c|c|c|c|}
\hline \multirow[t]{2}{*}{ Measurement } & \multicolumn{2}{|l|}{ TO } & \multicolumn{2}{|l|}{ T1 } & \multicolumn{2}{|l|}{ T1-T0 } & \multirow[t]{2}{*}{$P$-value } \\
\hline & Mean & SD & Mean & SD & Mean & SD & \\
\hline ANB $\left(^{\circ}\right)$ & 4.18 & 1.40 & 3.72 & 1.74 & -0.45 & 1.11 & 0.02 \\
\hline SNA $\left({ }^{\circ}\right)$ & 83.35 & 3.37 & 82.81 & 3.80 & -0.54 & 1.48 & 0.12 \\
\hline $\operatorname{SNB}\left({ }^{\circ}\right)$ & 79.17 & 3.11 & 79.09 & 3.74 & -0.08 & 1.50 & 0.19 \\
\hline U1-L1 ( $\left.{ }^{\circ}\right)$ & 109.39 & 7.32 & 131.77 & 10.00 & 22.38 & 10.87 & $<0.01$ \\
\hline U1-NA $\left({ }^{\circ}\right)$ & 31.28 & 5.58 & 19.68 & 7.49 & -11.60 & 6.23 & $<0.01$ \\
\hline L1-NB $\left(^{\circ}\right)$ & 35.37 & 4.15 & 25.16 & 5.34 & -10.21 & 7.20 & $<0.01$ \\
\hline SN-MP $\left({ }^{\circ}\right)$ & 33.20 & 5.92 & 34.14 & 5.33 & 0.94 & 2.73 & 0.05 \\
\hline FMA $\left({ }^{\circ}\right)$ & 27.15 & 5.41 & 27.37 & 5.32 & 0.22 & 3.03 & 0.67 \\
\hline Stmi-Me' (mm) & 44.14 & 3.03 & 44.38 & 2.50 & 0.24 & 1.95 & 0.47 \\
\hline
\end{tabular}

Table 4 Changes in the soft tissue area between pre-treatment (T0) and post-treatment (T1)

\begin{tabular}{|c|c|c|c|c|c|c|c|}
\hline \multirow[t]{2}{*}{ Measurement } & \multicolumn{2}{|l|}{ T0 } & \multicolumn{2}{|l|}{$\mathrm{T} 1$} & \multicolumn{2}{|l|}{ T1-T0 } & \multirow[t]{2}{*}{$P$-value } \\
\hline & Mean & SD & Mean & SD & Mean & SD & \\
\hline Area $1\left(\mathrm{~cm}^{2}\right)$ & 2.86 & 0.44 & 3.01 & 0.55 & 0.14 & 0.50 & 0.08 \\
\hline Area $2\left(\mathrm{~cm}^{2}\right)$ & 2.17 & 0.57 & 2.14 & 0.62 & -0.03 & 0.40 & 0.69 \\
\hline Area $1+2\left(\mathrm{~cm}^{2}\right)$ & 5.03 & 0.83 & 5.15 & 0.99 & 0.12 & 0.76 & 0.35 \\
\hline
\end{tabular}

retractions of upper incisors and lower incisors, respectively) (Table 7).

\section{Discussion}

The accuracy of prediction in the changes of the soft tissue chin area after orthodontic treatment using cephalogram is still poorly understood. The relationship between incisor movement and soft tissue change is still controversial. This may be because the soft tissue changes can be affected by not only incisor movement but also many other factors, such as dentofacial morphology, age, sex, ethnicity, soft tissue thickness and tension, and the technologies used for estimation [17, 18]. To minimize the influence of sex on soft tissue changes following the incisor movement, only female patients were included in this study.

Some studies have reported that the ratio between lip change and incisor retraction ranged from 1:0.45 to 1.25 for the upper lip, and from 1:1.2 to 1:6.2 for the lower lip in nongrowing patients with bimaxillary protrusion $[19,20]$. In addition to the changes of lip position, the incisor retraction could also induce soft tissue thickness changes $[19,21]$. In the current study, after incisor retraction $(5.35 \pm 1.79 \mathrm{~mm}$ and $4.42 \pm 1.62 \mathrm{~mm}$ for the upper and lower, respectively), the soft tissue thickness of L1c-LL, B-B' and Pog-Pog' increased 0.64 $\pm 1.67 \mathrm{~mm}$, $-1.21 \pm 1.34 \mathrm{~mm}$ and $0.44 \pm 1.10 \mathrm{~mm}$, respectively. This may be due to the reduced tension and deformation of the muscles around the lower lip, such as orbicularis oris and mentalis [14]. Another reason may be the thickness measured in the study, in fact, included the real thickness of the lower lip as well as the labial vestibule, which may also re-arrange after incisor retraction [17]. The rotation of the mandible could also influence the tension of soft tissues around the chin area. However, no statistically significant change existed in SN-MP and Stimi-Me'

Table 5 Changes in the soft tissue thickness between pretreatment (T0) and post-treatment (T1)

\begin{tabular}{|c|c|c|c|c|c|c|c|}
\hline \multirow[t]{2}{*}{ Measurement } & \multicolumn{2}{|l|}{ T0 } & \multicolumn{2}{|l|}{ T1 } & \multicolumn{2}{|l|}{ T1-T0 } & \multirow[t]{2}{*}{$P$-value } \\
\hline & Mean & SD & Mean & SD & Mean & SD & \\
\hline L1c-LL (mm) & 10.36 & 1.70 & 11.00 & 1.61 & 0.64 & 1.67 & 0.03 \\
\hline $\mathrm{B}^{-B^{\prime}}(\mathrm{mm})$ & 12.09 & 1.64 & 10.89 & 1.55 & -1.21 & 1.34 & $<0.01$ \\
\hline Pog-Pog' (mm) & 10.44 & 1.69 & 10.89 & 1.64 & 0.44 & 1.10 & 0.02 \\
\hline
\end{tabular}


Table 6 Pearson correlation coefficients between the incisor retraction, ANB, SN-MP and soft tissue thickness changes

\begin{tabular}{|c|c|c|c|c|c|c|c|c|}
\hline \multirow{2}{*}{$\begin{array}{l}\text { Soft tissue } \\
\text { thickness } \\
\text { changes }\end{array}$} & \multicolumn{2}{|l|}{ Upper incisor retraction } & \multicolumn{2}{|l|}{ Lower incisor retraction } & \multicolumn{2}{|l|}{ ANB } & \multicolumn{2}{|l|}{ SN-MP } \\
\hline & Correlation coefficient & $P$-value & Correlation coefficient & $P$-value & Correlation coefficient & $P$-value & Correlation coefficient & $P$-value \\
\hline$\overline{L 1-L L}$ & -0.22 & $P=0.19$ & 0.16 & $P=0.34$ & 0.230 & $P=0.17$ & 0.126 & $P=0.46$ \\
\hline$B^{-} B^{\prime}$ & -0.26 & $P=0.12$ & -0.38 & $P<0.05$ & 0.080 & $P=0.64$ & 0.200 & $P=0.23$ \\
\hline Pog-Pog' & -0.05 & $P=0.79$ & -0.04 & $P=0.83$ & 0.273 & $P=0.10$ & 0.122 & $P=0.47$ \\
\hline
\end{tabular}

before and after treatments. Moreover, although ANB decreased $0.45 \pm 1.11^{\circ}$ after treatments, no correlation was found between the change of ANB and the change of soft tissue thicknesses. One possible explanation is that the change of ANB was clinically inconspicuous in our study.

As for the thickness change of the lower lip, Kuhn found that the lower lip thickness decreased about $2.5 \mathrm{~mm}$ in patients with extraction treatments [22]. Some studies, on the other hand, found that the thickness of the lower lip increased [23]. They attributed these lip thickness changes to the muscular tension and deformation of lips, as well $[17,24,25]$. Nevertheless, many studies found no significant change in the lower lip thickness after incisor retractions $[22,26]$. The multiple regression analysis in our study showed that the thickness of L1c-LL was affected by the retraction of upper and lower incisors at the same time. Many scholars detected that the upper incisors had effects on the shape and position of the lower lip, probably because the lower lip often covers the upper incisor by a third [2].

The majority of studies found the thickness of B-B' had decreased [17, 24, 27], which are consistent with our study. The Pearson coefficient showed a negative correlation between the soft tissue thickness change of B-B' and the retraction of the lower incisor. The average change of soft tissue thickness of B-B' was less than zero. Thus, the more the retraction, the larger the thickness reduction of B-B' within limits. Unfortunately, the changes of soft tissue thickness around the chin area following incisor retraction are still inconclusive, especially for the change of Pog-Pog' which was found to increase, decrease or stay the same after tooth extraction [13].

Most of the previous studies on soft tissue changes were focused on linear or/and angular measurements using conventional two-dimensional cephalograms; a few studies investigated the soft tissue area changes $[8,28]$. The changes of soft tissue are complicated; therefore, we need

Table 7 Multivariate regression analysis of the incisor retraction and soft tissue thickness changes

\begin{tabular}{llllll}
\hline Soft tissue thickness changes & $R^{2}$ & $P$-value & Constant & $a$ & $b$ \\
\hline L1C-LL & 0.164 & 0.047 & 1.02 & -0.42 & 0.42 \\
B-B' & 0.142 & 0.022 & 0.17 & - & -0.31 \\
\hline
\end{tabular}

various kinds of data to get a more consummate prediction. The thickness and volume changes of the soft tissue could give us a rounded analysis of a certain area that couldn't be provided by the changes of merely linear or/ and angular measurements. For example, Dai detected the buccal facial depth decreased in adult female patients undergoing extraction by using a three-dimensional structured light scanning system [29]. To measure the volume changes, $\mathrm{CBCT}$ scanning is preferable. However, this is not quite applicable so far due to ethical and technique reasons. Thus, measurements of the area on $2 \mathrm{D}$ cephalogram remain a practical approach. In this study, besides the linear and angular measurements on the cephalography, incisor retractions, and soft-tissue thicknesses, the areas of soft tissue chin and lower lip were also measured using a digital planimeter [16]. It was found that the muscle tension around the chin region decreased with the degree of maxillary incisor retraction, which might increase the area of the soft tissues around the chin [14]. However, no significant change was found in the areas of the soft tissue chin and lower lip in the study. This may because the soft tissues around the chin region are relatively attached to the basal bone with less mobility. According to this finding, the areas of soft tissue chin and lower lip should be set as invariants in software programming. Based on this rule, a more accurate prediction could be made for the morphological changes of the soft tissue chin combined with the changes of other anatomical landmarks after incisor retractions. Also, if the area of soft tissue chin was found increased after treatments, we would highly suspect that filling material existed in the soft tissue chin.

Apart from the fact that the measurements in the study were two-dimensional and performed on lateral cephalometric radiographs, other limitations of the study may also restrict the generalization of the results, for example, samples were all young female adults and of Asian ethnicity. Studies in the future could include both men and women with a wide range of age and ethnicity, and consider using three-dimensional techniques, such as CT and stereophotogrammetry [29], in order to get a more accurate prediction of the soft tissue changes following different types of tooth movements.

\section{Conclusions}

The area of soft tissue chin and lower lip did not change significantly after orthodontic incisor retraction in female 
young adult patients with bimaxillary protrusion. Following the incisor retraction, the soft tissue thicknesses of L1c-LL and Pog-Pog' increased, while in the soft tissue thickness of B-B' decreased. High-quality and welldesigned prospective trials are needed in order to make a more accurate conclusion.

\section{Abbreviations}

VTO: Visual treatment objective; CBCT: Cone-beam computed tomography; FH: Frankfort Horizontal

\section{Acknowledgements}

Not applicable.

\section{Authors' contributions}

WL and XZ made substantial contributions to the design of the work, the analysis of the data and the drafting of the manuscript. LM made substantial contributions to the concept of the study, drafting of the manuscript and critical revision for important intellectual content. PW and JH made substantial contributions to the measurements of lateral cephalograms and the preparation of figures and Tables. YL and ZZ supervised the whole study and made substantial contribution to the concept of the study and critical revision for the important intellectual content. All authors read and approved the final manuscript.

\section{Funding}

This study was supported by National Natural Science Foundation of China (NSFC) [project No.31971247] and Science and Technology Department of Sichuan Province [project No. 2018SZ0379]. The funding has no competing interests with the study. The funding body has no conflict of interest in the design of the study and collection, analysis, interpretation of data and in writing the manuscript.

\section{Availability of data and materials}

The datasets used and/or analyzed during the current study are available from the corresponding author on reasonable request.

\section{Ethics approval and consent to participate}

Ethical approval for the study was obtained from the Ethics Committee of the West China Hospital of Stomatology, Sichuan University (WCHSIRB-ST2017-131). Written informed consent was obtained from each participant.

\section{Consent for publication}

Not applicable.

\section{Competing interests}

The authors declare that they have no competing interests.

Received: 15 September 2019 Accepted: 30 March 2020

Published online: 15 April 2020

\section{References}

1. Matoula S, Pancherz H. Skeletofacial morphology of attractive and nonattractive faces. Angle Orthd. 2006;76:204-10.

2. Bourzgui F, Alami S, Sebbar M, Derkaoui T, Hamza M, Serhier Z, et al. Effect of orthodontic treatment on lip position. Int Orthod. 2013:11:303-13.

3. Zide BM, McCarthy J. The mentalis muscle: an essential component of chin and lower lip position. Plast Reconstr Surg. 1989:83:413-20.

4. lared W, Em KDS, lared W, Rufino MC. Esthetic perception of changes in facial profile resulting from orthodontic treatment with extraction of premolars: a systematic review. J Am Dent Assoc. 2016;9:1-7.

5. Kirschneck C, Proff P, Reicheneder C, Lippold C. Short-term effects of systematic premolar extraction on lip profile, vertical dimension and cephalometric parameters in borderline patients for extraction therapy-a retrospective cohort study. Clin Oral Investig. 2016;20:865-74.

6. Veltkamp T, Buschang PH, English JD, Bates J, Schow SR. Predicting lower lip and chin response to mandibular advancement and genioplasty. Am J Orthod Dentofac Orthop. 2002;122:628-34.
7. Mobarak KA, Krogstad O, Espeland L, Lyberg T. Factors influencing the predictability of soft tissue profile changes following mandibular setback surgery. Angle Orthod. 2001;71:216-27.

8. Peterman RJ, Jiang $\mathrm{S}$, Johe R, Mukherjee PM. Accuracy of dolphin visual treatment objective (VTO) prediction software on class III patients treated with maxillary advancement and mandibular setback. Prog Orthod. 2016;17:1-9.

9. De Lira ADLS, de Moura WL, Artese F, Bittencourt MAV, Nojima LI. Surgical prediction of skeletal and soft tissue changes in treatment of class II. J Cranio Maxilla Surg. 2013;41:198-203.

10. Merrifield LL. The profile line as an aid in critically evaluating facial esthetics. Am J Orthod. 1966:52:804-22.

11. Wen J, Liu S, Ye X, Xie X, Li J, Li H, et al. Comparative study of cephalometric measurements using 3 imaging modalities. J Am Dent Assoc. 2017:148:1-9.

12. Tan SSW, Ahmad S, Moles DR, Cunningham SJ. Picture archiving and communications systems: a study of reliability of orthodontic cephalometric analysis. Eur J Orthod. 2011;33:537-43.

13. Hayashida H, loi H, Nakata S, Takahashi I, Counts AL. Effects of retraction of anterior teeth and initial soft tissue variables on lip changes in Japanese adults [J]. Eur J Orthod. 2011;33:419-26.

14. Yun-Hee YH, Yae-Jin K, Dong-Yul L, Yong-Kyu L. The predictability of dentoskeletal factors for soft-tissue chin strain during lip closure. Korean J Orthod. 2013:43:279-87.

15. Kim K, Choi SH, Choi EH, Choi YJ, Hwang CJ, Cha JY. Unpredictability of soft tissue changes after camouflage treatment of class II division 1 malocclusion with maximum anterior retraction using miniscrews. Angle Orthod. 2017:87:230-8

16. Altugatac AT, Bolatoglu H, Memikoglu UT. Facial soft tissue profile following bimaxillary orthognathic surgery. Angle Orthod. 2008:78:50-7.

17. Aniruddh YV, Ravi K, Arumugam E. Comparative evaluation of soft tissue changes in class I borderline patients treated with extraction and nonextraction modalities. Dental Press J Orthod. 2016:21:50-9.

18. Anic-Milosevic S, Mestrovic S, Prlić A. Proportions in the upper lip-lower lipchin area of the lower face as determined by photogrammetric method. J Cranio Maxilla Surg. 2010;38:90-5

19. Leonardi R, Annunziata A, Licciardello V, Barbato E. Soft tissue changes following the extraction of premolars in nongrowing patients with bimaxillary protrusion. A systematic review. Angle Orthod. 2010:80:211-6.

20. Ahn HW, Chang YJ, Kim KA, Joo SH, Park YG, Park KH. Measurement of three-dimensional perioral soft tissue changes in dentoalveolar protrusion patients after orthodontic treatment using a structured light scanner. Angle Orthod. 2014;84:795-802

21. Janson G, Mendes LM, Junqueira CH, Garib DG. Soft-tissue changes in class II malocclusion patients treated with extractions: a systematic review. Eur J Orthod. 2015:6:1-7.

22. Kuhn M, Markic G, Doulis I, Göllner P, Patcas R, Hänggi MP. Effect of different incisor movements on the soft tissue profile measured in reference to a roughsurfaced palatal implant. Am J Orthod Dentofac Orthop. 2016;149:349-58.

23. Kim K, Choi SH, Choi EH, Choi YJ, Hwang CJ, Cha JY. Unpredictability of soft tissue changes after camouflage treatment of class II division 1 malocclusion with maximum anterior retraction using miniscrews. Angle Orthod. 2016;87:230-8.

24. Hodges A, Rossouw PE, Campbell PM, Boley JC, Alexander RA, Buschang PH. Prediction of lip response to four first premolar extractions in white female adolescents and adults. Angle Orthond. 2009;79:413-21.

25. Oliver BM. The influence of lip thickness and strain on upper lip response to incisor retraction. Am J Orthod Dentofac Orthop. 1982;82:141-9.

26. Brock RA II, Taylor RW, Buschang PH, Behrents RG. Ethnic differences in upper lip response to incisor retraction. Am J Orthod Dentofac Orthop. 2005:127:683-91.

27. Shivani A, Sadeghian S, Abbasi S. Prediction of lip response to orthodontic treatment using a multivariable regression model. Dent Res J. 2016;13:38

28. Lee YJ, Park JT, Cha JY. Perioral soft tissue evaluation of skeletal class II division 1: a lateral cephalometric study. Am J Orthod Dentofac Orthop. 2015;148:405-13.

29. Fanfan D, Jie Y, Gui C, Tianmin X, Ruoping J. Changes in buccal facial depth of female patients after extraction and nonextraction orthodontic treatments: a preliminary study. Korean J Orthod. 2018;48:172-81.

\section{Publisher's Note}

Springer Nature remains neutral with regard to jurisdictional claims in published maps and institutional affiliations. 